\title{
Efeitos do estresse térmico na produção de vacas leiteiras: Revisão
}

\author{
Aurélio Ferreira Melo1, Juracy Mendes Moreira², Daniela Silva Ataídes², Rosiane \\ Aparecida Macedo Guimarães ${ }^{2}$, Jorge Lima Loiola ${ }^{2}$, Helbio Carlos Sardinha ${ }^{3}$ \\ ${ }^{\text {I} P r o f . ~ F a c u l d a d e ~ A l m e i d a ~ R o d r i g u e s ~(F A R), ~ D o u t o r a n d o ~ e m ~ C i e ̂ n c i a s ~ A g r a r i a s ~ p e l o ~ I n s t i t u t o ~ F e d e r a l ~ G o i a n o ~ C a m p u s ~ R i o ~}$ \\ Verde-GO, Brasil. \\ ${ }^{2}$ Professor(a) da Faculdade Almeida Rodrigues (FAR), Rio Verde - GO, Brasil. \\ ${ }^{3}$ Zootecnista pelo Instituto Federal Goiano, Campus Rio Verde - GO, Brasil \\ *Autor para correspondência: E-mail: aurelioferreiramelo1@ @otmail.com
}

\begin{abstract}
RESUMO. O Brasil apresenta destaque na produção mundial de leite, ocupando a quinta posição dentre os maiores produtores. Goiás ocupa a quarta posição no ranking dos estados produtores de leite, com perspectivas de aumento ao longo dos anos. Objetivou-se com este estudo descrever os efeitos do estresse térmico na produção de vacas leiteiras. $\mathrm{O}$ estresse térmico influencia na produção e composição centesimal do leite, tornando fundamental o fornecimento de ambiente que proporcione o conforto térmico aos animais. As variações sazonais influenciam na qualidade e quantidade de leite produzido, sendo que animais de origem indiana (Bos indicus) são mais tolerantes ao clima tropical, quando comparado com animais de origem europeia (Bos taurus), em virtude de sua maior capacidade de transpiração e menor taxa metabólica. Contudo, é certo, a necessidade de investimentos em instalações que possibilite ambientes com condições mínimas de temperatura e umidade relativa do ar, o que favorece o aumento produtivo e a melhoria da qualidade do leite produzido.
\end{abstract}

Palavras chave: Leite in natura, cruzamento, composição química, produção

\section{Effects of stress in thermal cows milk production: Review}

\begin{abstract}
Brazil has highlighted the world's milk production, ranking fifth among the largest producers. Goiás ranks fourth in the ranking of states that produce milk with increased prospects over the years. The objective of this study describe about the effects of heat stress in the production of dairy cows. Heat stress influences the production and chemical composition of the milk, environment supply the making fundamental that provides thermal comfort to the animals. Seasonal variations influence the quality and quantity of milk produced, and animals of Indian origin (Bos indicus) are more tolerant to the tropical climate, when compared with European origin of animals (Bos taurus), because of their greater ability to sweat and lower metabolic rate. However is right, the need for investment in facilities to enable environments with minimal conditions of temperature and relative humidity, which favors the production increase and improve the quality of milk produced.
\end{abstract}

Keywords: Milk in nature, crossing, chemical composition, production

\section{Introdução}

Leite é o produto obtido pela ordenha manual ou mecânica completa, sem interrupção, em ótimas condições higiênicas, coletado de vacas sadias, bem alimentadas e descansadas (Porto et al., 2009). O leite é um fluído composto de água, lactose, gordura, proteínas (principalmente caseína), minerais e vitaminas (Goetsch et al., 2011).

Dos 5.562 municípios existentes no Brasil são raros os que não desenvolvem a atividade leiteira (Gomes, 1999). O Brasil é o quinto maior produtor de leite do mundo, apresentando constante crescimento da 
produção leiteira. Em 2011, a produção nacional foi de 32,2 bilhões de litros de leite, com 23,508 milhões de vacas ordenhadas, com média de 1.374 litros/vaca/ano (ANUALPEC, 2015).

No ranking dos estados produtores de leite no Brasil se destacam Minas Gerais, Rio Grande do Sul e Paraná. Goiás ocupa a quarta posição, com produção média de 3,193 bilhões de litros de leite em 2010, e perspectivas de aumento de $6,3 \%$ em relação a 2009 (ANUALPEC, 2015).

A importância socioeconômica pode ser constatada pela posição que ocupa no agronegócio brasileiro, ou seja, é um dos principais setores de geração de renda nacional e arrecadação tributária de acordo com a Organização das Nações Unidas para Alimentação e Agricultura (FAO, 2015). O consumo per capita brasileiro, no ano de 2009, segundo os dados da Pesquisa Pecuária Municipal do IBGE, ficou em torno de 152 litros por habitante.

As indústrias de leite e derivados vêm se modernizando em todo o país e a qualidade da matéria prima é um dos maiores entraves ao desenvolvimento do setor leiteiro. De maneira geral o controle de qualidade do leite é baseado nas determinações físico-químicas como acidez titulável, densidade, gordura, sólidos totais, contagem bacteriana total (CBT) e contagem de células somáticas (CCS) (Pereira et al., 1999; Prada et al., 2000).

A produção de leite in natura em condições higiênico-sanitárias inadequadas torna-se um entrave para as indústrias lácteas, pois diminui o rendimento de fabricação dos derivados lácteos, além de comprometer a qualidade do produto final.

O estresse calórico é um típico problema encontrado no manejo de vacas leiteiras nos trópicos e sub trópicos, causando reduções na produção e mudanças na composição físicoquímica do leite, redução na ingestão de alimentos e aumento na ingestão de água, a perda de produção de leite devido ao aumento de temperatura depende de fatores como a umidade relativa do ar, velocidade do vento, nutrição e outros fatores relacionados ao manejo (Berman, 2011; Head, 1989).

Segundo Fagan et al. (2010) as temperaturas críticas superiores e inferiores, delimitam a faixa de termo neutralidade para animais, pois o conforto térmico depende também da umidade relativa do ar, da capacidade adaptativa do animal, do metabolismo e do período produtivo.

Em relação à tolerância ao calor existe diferença genética, pois animais Bos indicus são mais termo tolerantes do que animais Bos taurus, em virtude da maior capacidade de transpiração e menor taxa metabólica. O estresse calórico pode resultar em um decréscimo de $17 \%$ na produção de leite de vacas de $15 \mathrm{~kg}$ de leite/dia e de $22 \%$ em vacas de $40 \mathrm{~kg}$ de leite dia (Pinarelli, 2003).

Além da redução no consumo de alimentos, as respostas das vacas em lactação ao estresse térmico incluem a redução na produção e porcentagem de gordura no leite, redução no consumo de forragem como porcentagem do total de alimento, aumento das necessidades de manutenção, diminuição da atividade, especialmente durante o dia e aumento da frequência respiratória e hipertermia (Baccari Júnior, 2001).

A melhor condição de conforto térmico proporcionada por sombra natural, não diz respeito apenas à presença de árvores nos piquetes de criação bovina, mas sim à utilização de sombrites artificiais, que proporcionam uma melhor condição de conforto aos bovinos do que a presença de árvores com distribuição isolada nas pastagens (Aguiar \& Targa, 1999).

Diante do exposto o objetivo desta revisão é abordar aspectos relacionados ao estresse térmico em vacas leiteiras e as alterações relacionadas à qualidade e produção do leite.

\section{Composição físico química do leite}

O leite é o produto oriundo da ordenha completa e ininterrupta, em condições de higiene, de vacas sadias, bem alimentadas e descansadas, o leite de outros animais deve ser denominado segundo a espécie de que proceda (Goetsch et al., 2011). É considerado o mais nobre dos alimentos, pois é rico em proteína, gordura, carboidratos, sais minerais e vitaminas, proporciona nutrientes e proteção imunológica para o neonato, além das propriedades nutricionais, oferece elementos anticarcinogênicos, presentes na gordura, como o ácido linoléico conjugado, 
esfingomielina, ácido butírico, $\beta$ caroteno e vitaminas A e D (Oliveira et al., 1999).

O conhecimento da composição do leite é essencial para a determinação de sua qualidade, pois define diversas propriedades sensoriais e industriais (Noro et al., 2006). Além disso, a composição do leite determina as suas propriedades tecnológicas de processamento de seus subprodutos como queijo, manteiga, iogurte, e entre outros produtos lácteos (Glantz et al., 2009). A água é o componente mais abundante no leite, no qual se encontram em solução os sólidos totais (ST) ou extrato seco total (EST) que englobam todos os componentes do leite, exceto a água, para sólidos não gordurosos (SNG) ou extrato seco desengordurado (ESD), compreendem-se todos os elementos do leite, menos água e gordura (Tronco, 2008). O leite de vacas sadias contém em média $87,1 \%$ de água, 3,0\% de gordura, $2,9 \%$ de proteína, $4,6 \%$ de lactose, $8,4 \%$ de extrato seco desengordurado (ESD) e 0,7\% de cinzas (Silva et al., 2008). Informações sobre a composição média do leite de diversas espécies são fornecidas na Tabela 1. De acordo com a Instrução Normativa $\mathrm{n}^{\circ} 62$ (2011) a densidade do leite bovino a $15^{\circ} \mathrm{C}$ deve ser de $1,028 \mathrm{~g} / 100 \mathrm{~mL}$ a $1,034 \mathrm{~g} / 100$ $\mathrm{mL}$, a acidez titulável de 0,14 a $0,18 \mathrm{~g}$ de ácido láctico/100 mL, e índice crioscópico máximo de $-0,530{ }^{\circ} \mathrm{H}$ (BRASIL, 2011). A composição do leite pode variar de acordo com a raça, período de lactação, alimentação, saúde, período de cio, idade, características individuais, clima, espaço entre as ordenhas, estação do ano, manipulação, ação de microorganismos, fatores nutricionais, fraudes do produto (Padilha \& Fernandes, 1999) por fatores ambientais, onde se destacam, principalmente, fases da lactação e intervalo entre as ordenhas (Behmer, 1975). A fase de lactação representa importante fator de variação nas características de composição do leite, pesquisas indicam que os valores de proteína, lipídios e lactose aumentam no decorrer da lactação (Aganga et al., 2002).

Tabela 1. Composição média do leite de diferentes espécies.

\begin{tabular}{lcccc}
\hline Espécie & Gordura, $\%$ & Proteína & Lactose & Cinzas \\
\hline Humana & 4,5 & 1,1 & 6,8 & 0,2 \\
Bovina & $3,5-5,5$ & 3,6 & 4,9 & 0,7 \\
Ovina & 6,3 & 5,5 & 4,6 & 0,9 \\
Caprina & 4,1 & 4,2 & 4,6 & 0,8 \\
Leporina & 12,2 & 10,4 & 1,8 & 2,0 \\
\hline
\end{tabular}

Fonte: Cerdótes et al. (2004).

A lactose é o componente mais abundante, o mais simples e o mais constante em proporção, encontrando-se em quantidades compreendidas entre 40 e $50 \mathrm{~g} /$ litro (Cerdótes et al., 2004). Normalmente, a menos que os animais estejam muito subnutridos, a concentração de lactose no leite não é afetada por fatores nutricionais (González et al., 2001). Minerais como o cálcio e o fósforo estão presentes em aproximadamente $1 \%$ do leite (Vaclavik \& Christian, 2007). Existem ainda diversos minerais em quantidades pequenas, a saber: sódio, potássio, magnésio, flúor, iodo, cobre, zinco e ferro (Tronco, 2008).

\section{Legislação brasileira de qualidade do leite}

A produção de leite no Brasil acompanhou o processo de urbanização, as bacias leiteiras se formaram com o propósito de atender o mercado de consumidores das cidades (Carvalho et al., 2006).

O produtor é incentivado a melhorar, porque participa de programas de pagamento por qualidade, e o consumidor mais consciente, passou a exigir da indústria produtos com certificados de garantia de qualidade e rastreabilidade (Sá et al., 2011). A mudança de maior impacto foi à refrigeração do leite na fonte de produção e o transporte a granel regulamentado pela Instrução 
Normativa $\mathrm{n}^{\circ} 51$, de 18 de setembro de 2002 (BRASIL, 2002).

As características físico-químicas do leite e suas inter-relações constituem uma valiosa ferramenta para avaliar o desempenho produtivo dos rebanhos leiteiros, informar sobre o estado fisiológico da lactação e para diagnosticar distúrbios de metabolismo e seus possíveis impactos sobre o processamento industrial e a qualidade final dos produtos lácteos (Ponce, 2009).

Informações sobre os requisitos físicos e químicos do leite cru refrigerado de acordo com a IN 62 são fornecidas na Tabela 2.

Tabela 2. Requisitos físicos e químicos do leite cru refrigerado de acordo com a IN 62.

\begin{tabular}{lc}
\hline Requisitos & Limites \\
\hline Acidez titulável, g ác. láctico/100mL & 0,14 a 0,18 \\
Densidade relativa a $15^{\circ} \mathrm{C} \mathrm{g} / \mathrm{mL}$ & 1,028 a 1,034 \\
Crioscopia máxima & $-0,530^{\circ} \mathrm{H}\left(-0,512^{\circ} \mathrm{C}\right)$ \\
Matéria gorda, g/100g & Teor original, com o mínimo 3 \\
Extrato seco desengordurado, g/100g & Mínimo 8,4 \\
Proteínas, g/100g & Mínimo 2,9 \\
\hline
\end{tabular}

Fonte: BRASIL, (2011).

De maneira geral o controle de qualidade do leite é baseado nas determinações físicoquímicas como acidez titulável, densidade, gordura, sólidos totais, contagem bacteriana total (CBT) e contagem de células somáticas (CCS). As análises laboratoriais mais utilizadas para monitorar a qualidade microbiológica do leite cru são a contagem bacteriana total (CBT) que quantifica o número total de bactérias presentes no leite cru, mas não identifica grupos específicos de bactérias que se proliferam quando há falhas nos processos de produção, ordenha $\mathrm{e}$ armazenamento (Nickerson et al., 1995). E a contagem de células somáticas (CCS) no leite bovino é usada como uma medida da saúde da glândula mamária e da qualidade do leite, a presença de elevadas contagens de células somáticas afetam o tempo de prateleira dos derivados e ocasiona a inibição do crescimento de culturas starters para a produção de derivados lácteos, causando enormes prejuízos nas indústrias de laticínios (Tronco, 2008). A CCS do leite de uma vaca indica de maneira quantitativa o grau de infecção da glândula mamária, já o leite do tanque de expansão indica a incidência média de mastite no rebanho. O entendimento da dinâmica da CCS de tanques é um importante passo para a melhoria da qualidade do leite (Machado et al., 2000).

Outras análises podem ser utilizadas para avaliar a qualidade do leite, como a contagem de coliformes, que é utilizada em programas de qualidade como indicador de contaminação fecal, a partir do solo, cama dos animais e água contaminada (Brito, 1999). Machado (1998) observou que no verão há uma elevação na porcentagem de novas infecções na glândula mamária, o que pode indicar maior quantidade de bactérias presentes na superfície dos tetos e/ou menor resistência imunológica. A adaptação ao meio ambiente modifica esses graus de resposta e permite determinar indiretamente, através do desempenho, como os animais são afetados na produção e reprodução (Uribe-Velásquez et al., 2001).

\section{Fatores que afetam a qualidade do leite}

Por causa do valor nutricional, a disponibilidade de nutrientes, a alta quantidade de água e o pH próximo da neutralidade o leite é extremamente favorável ao crescimento de vários grupos de microrganismos desejáveis e indesejáveis (Chen et al., 2010).

A qualidade e a segurança alimentar têm recebido cada vez mais atenção da população mundial, especialmente em relação a perigos microbiológicos presentes em alimentos (Nero et al., 2007). Apesar da importância do controle de qualidade na produção, o leite produzido e consumido no Brasil tem se caracterizado pela informalidade e por uma 
qualidade questionável, muitas vezes fora dos padrões internacionais (Alves et al., 2008).

Segundo Monardes (2008), a cadeia leiteira brasileira tem iniciado um processo sério de monitoramento da qualidade do leite in natura, que deve servir não só para observar e qualificar a matéria-prima, mas também para melhorar os processos produtivos das propriedades leiteiras.

A ação das bactérias ou enzimas sobre os componentes lácteos causa várias alterações no leite e derivados, esses defeitos incluem sabores e aromas indesejáveis, diminuição da vida de prateleira, interferência nos processos tecnológicos e redução dos rendimentos (Champagne et al., 1994).

Muitas bactérias contaminantes do leite cru produzem enzimas extracelulares (proteases e lipases) termo resistentes, cuja atividade residual afeta a qualidade dos produtos finais, mesmo na ausência de células bacterianas viáveis, a contaminação bacteriana do leite cru pode ocorrer a partir do próprio animal, do homem e do ambiente, exceto em casos de mastite, o leite ejetado apresenta baixo número de microrganismos, que não constituem riscos à saúde (Chen et al., 2003). As principais enzimas envolvidas na deterioração do produto são as proteases e lipases, glicosidases, fosfatases e esterases, embora nem todas essas sejam produzidas por bactérias, fatores ambientais como temperatura, $\mathrm{pH}$ e aeração também podem influenciar a síntese e ação dessas enzimas (Chen et al., 2010).

Do ponto de vista tecnológico, os microorganismos de maior importância são os que contaminam o leite durante e após a ordenha, essa contaminação é variável, tanto qualitativa quanto quantitativa, em função das condições de higiene existentes (Froeder et al., 1985). Microrganismos indicadores são grupos ou espécies que, quando presentes no alimento, podem fornecer informações sobre a contaminação fecal, com provável presença de patógenos ou com deterioração potencial do alimento, além de indicarem condições sanitárias inadequadas durante o processamento e produção, são representados principalmente pelos gêneros Klebsiella, Escherichia, Citrobacter e Enterobacter que fermentam a lactose, produzindo ácido e gás quando incubados a $35^{\circ} \mathrm{C}$ por $24-48 \mathrm{~h}$ (Silva et al.,
1997). A obtenção do leite de vacas sadias, em condições higiênicas adequadas, e o seu resfriamento imediato a $4^{\circ} \mathrm{C}$ são as medidas fundamentais e primárias para garantir a qualidade e a segurança do leite e derivados.

\section{Influência do estresse calórico na produção e qualidade do leite}

Altas temperaturas durante o verão são estressantes para bovinos, bubalinos, caprinos, ovinos e suínos, devido à incapacidade de manterem a termo regulação eficiente, apresentando quadros de hipertermia, resultado da inabilidade de dissipar o calor corporal, perturbando o mecanismo termo regulatório, bem como o surgimento de alterações adaptativas como alteração na ingestão de alimentos e água, decréscimo da produção de leite e do metabolismo basal (Jordan, 2003).

No Brasil, a temperatura média do ar está geralmente situada acima dos $20^{\circ} \mathrm{C}$, sendo que, nas horas mais quentes do dia, as temperaturas observadas permanecem acima dos $30^{\circ} \mathrm{C}$ em grande parte do ano, atingindo a faixa de $35^{\circ} \mathrm{C}$ a $38^{\circ} \mathrm{C}$ (Titto, 1998).

Segundo Azevedo et al. (2005), dois terços do território brasileiro está situado na região tropical, onde há predominância de altas temperaturas, consequentemente da alta incidência de radiação solar. $\mathrm{O}$ estresse térmico afeta negativamente vários aspectos da produção leiteira, atuando na diminuição da produção de leite e nas perdas reprodutivas, além de causar um impacto significativo no potencial econômico das fazendas produtoras de leite (Bilby et al., 2009).

O Sudoeste Goiano se localiza na altitude média de $748 \mathrm{~m}$, e o clima apresenta duas estações bem definidas, uma seca (de maio a outubro) e outra chuvosa (novembro a abril) com precipitação média de $1200 \mathrm{~mm} / \mathrm{ano}$. A temperatura média anual varia entre $20^{\circ} \mathrm{C}$ e $35^{\circ} \mathrm{C}$ (Santos \& Ribeiro, 2004).

De acordo com Nääs \& Arcaro Júnior (2001), a faixa de $13^{\circ} \mathrm{C}$ a $18^{\circ} \mathrm{C}$ mostrou-se confortável para a maioria dos ruminantes, enquanto que para vacas em lactação o melhor intervalo estaria entre $4^{\circ} \mathrm{C}$ e $24^{\circ} \mathrm{C}$, podendo ser restringida entre $7^{\circ} \mathrm{C}$ e $21^{\circ} \mathrm{C}$ em função da umidade relativa do ar e radiação solar. Huber (1990) reportou a zona de termo neutralidade 
de $4^{\circ} \mathrm{C}$ a $26^{\circ} \mathrm{C}$, para vacas holandesas em lactação.

A diminuição na produção de leite das vacas sob estresse térmico advindo de elevadas temperaturas deve-se, à redução no consumo de alimentos, com isso ocorre a hipofunção da tireóide e a energia despendida para eliminar o excesso de calor corporal (Baccari Júnior, 2001).

O estresse calórico pode resultar em uma diminuição de $17 \%$ da produção de leite de vacas de $15 \mathrm{~kg}$ de leite/dia e de $22 \%$ em vacas de $40 \mathrm{~kg} / \mathrm{dia}$ (Pinarelli, 2003). Além da redução no consumo de alimentos, as respostas das vacas em lactação ao estresse térmico incluem: redução na produção e porcentagem de gordura no leite, redução no consumo de forragem como porcentagem do total de alimento, quando oferecida separadamente, aumento das necessidades de manutenção, diminuição da atividade, especialmente durante o dia, aumento da frequência respiratória e hipertermia ((Baccari Júnior, 2001).

Deve-se considerar que, em condições de estresse calórico, ocorre também um aumento na ingestão de água (Perissinotto et al., 2006). Além disso, na época do ano em que há abundância de chuvas a alimentação restringese a pastagem, que apresenta um maior teor de água na composição, esses fatores somados podem provocar uma diluição dos sólidos totais do leite. Paralelamente à redução do consumo, há aumento do fluxo sanguíneo periférico para reduzir a temperatura corporal, ocasionando redução na absorção de nutrientes e na disponibilidade desses à glândula mamária (McGuire et al., 1989). Adicionalmente, nos períodos mais quentes do ano, as vacas holandesas utilizam mecanismos como redução no tempo de alimentação e ruminação, e aumento no tempo de ócio, provavelmente para diminuir a produção de calor metabólico excedente, pois o aumento do tempo de permanência em pé pode auxiliar na dissipação do calor, como tentativa dos animais em manter a homeotermia (Pires et al., 2002).

Em resposta ao estresse calórico, podem ainda ocorrer alterações metabólicas, há então, uma elevação do $\mathrm{pH}$ do plasma, o que ocasiona uma alcalose respiratória, paralelamente, em função do menor consumo alimentar, menor motilidade estomacal e predileção por alimentos concentrados (menor calor de fermentação no rúmen), há uma redução do $\mathrm{pH}$ ruminal, que, eventualmente, pode levar a uma maior produção de ácido lático (Machado, 1998).

A recuperação da produção de leite após o estresse calórico ocorre lentamente e em graus que variam com a intensidade e duração do estresse, além da fase da lactação, dentro dos limites fisiológicos da glândula mamária, podendo recuperar totalmente a produção normal ou até comprometer toda a lactação (Titto, 1998). No estudo realizado por Campos et al. (2008) foi observado uma diminuição da produção de leite quando os animais foram submetidos à temperatura de $32^{\circ} \mathrm{C}$ e a umidade relativa (UR) variando de $20 \%$ para $45 \%$, essa diferença de $25 \%$ na umidade inibe o resfriamento evaporativo em bovinos, resultando na elevação da temperatura retal, causando diminuição no consumo de alimento e, consequentemente, perdas na produção de leite.

A utilização correta de instalações e equipamentos, como ventiladores e aspersores, para reduzir o estresse térmico por calor pode melhorar a produtividade dos animais (Marcheto et al., 2002).

A composição do leite pode ser alterada pelo estresse calórico, com redução nos teores de gordura, proteína e cálcio (Titto, 1998), lactose, ácido cítrico e potássio (Ceballos et al., 2009). Os valores de sólidos totais (ST) do leite sofrem uma variação sazonal anual, aumentando durante o período de frio $\mathrm{e}$ diminuindo na época de calor e chuvas (Ponsano et al., 1999). De acordo com Collier (1985), os sólidos não-gordurosos também são menores durante os meses quentes, devido principalmente à variação no conteúdo proteico do leite.

$\mathrm{Na}$ maioria dos casos, a proteína do leite é negativamente afetada pelo estresse calórico, com decréscimo nos teores de caseína, os íons cálcio, fósforo e magnésio geralmente diminuem, enquanto os níveis de cloro aumentam. Os teores de gordura do leite diminuem quando as vacas são expostas a estresse calórico classificado como severo, os ácidos graxos de cadeia longa aumentam e os de cadeia curta diminuem (Bernabucci \& Calamari, 1998). Uma possível explicação 
para os menores teores de gordura observados no leite de vacas em situações de estresse calórico seria a variação no consumo de forrageiras pelos animais, sendo que o menor consumo de volumosos provoca uma alteração na razão acetato/propionato, alterando assim a composição do leite (Collier, 1985).

Pinarelli (2003) observou que, para vacas mantidas em baixas temperaturas, as médias dos teores de gordura, proteína e lactose foram de $3,47 \% ; 3,07 \%$ e $5,08 \%$ respectivamente, para vacas em temperatura intermediária foram de $3,46 \% ; 3,02 \%$ e 5,06\% e de $3,17 \% ; 2,89 \%$ e $5,01 \%$ para vacas mantidas em altas temperaturas.

Para cada situação há uma alternativa que se apresenta mais eficaz para amenizar os efeitos do estresse calórico sobre a produção e qualidade do leite, deve-se adotar medidas visando ao conforto térmico, considerando as características climáticas inerentes a cada propriedade e à região na qual se localiza, além das características do rebanho e a relação custo-benefício (Porcionato et al., 2009).

\section{Considerações finais}

A produção de leite é uma das principais atividades agropecuárias, que fornece alimento à população. Possui importância econômica, ou seja, é um dos principais setores de geração de renda nacional e arrecadação tributária.

Há um crescente aumento das exigências referente ao padrão de qualidade na obtenção do leite e derivados no Brasil, essa preocupação se dá para que o consumidor possa ter um alimento saudável e seguro.

O estresse térmico influencia na produção e composição centesimal do leite, tornando fundamental o fornecimento de ambiente que proporcione o conforto térmico aos animais. As variações sazonais influenciam na qualidade e quantidade de leite produzido, sendo que animais de origem indiana (Bos indicus) são mais tolerantes ao clima tropical, quando comparado com animais de origem europeia (Bos taurus), em virtude de sua maior capacidade de transpiração e menor taxa metabólica.

\section{Referências Bibliográficas}

Aganga, A. A., Amarteifio, J. O. \& Nkile, N.

(2002). Effect of stage of lactation on nutrient composition of Tswana sheep and goat's milk. Journal of Food Composition and Analysis, 15: 533-543.

Aguiar, I. S. \& Targa, L. A. (1999). Respostas termorreguladoras, armazenamento de calor corporal e produção de leite de vacas holandesas mantidas ao sol e com acesso à sombra natural. Energia na Agricultura 14: 9-21.

Alves, R. N., Paciulli, S. d. O. D. \& Teran, G. P. (2008). Influência da qualidade do leite "in natura" sobre as características físicoquímicas do leite pasteurizado na indústria de laticínios do CEFET-Bambui. I Jornada Científica e VI FIPA do CEFET 1: 1-5.

ANUALPEC. (2015). Anuário da Pecuária Brasileira. 20th ed. Instituto FNP, São Paulo, SP, Brasil.

Baccari Júnior, F. (2001). Manejo ambiental da vaca leiteira em climas quentes. EDUEL, Londrina.

Behmer, M. L. A. (1975). Tecnologia do leite: leite, queijo, manteiga, caseina, iogurte, sorvetes e instalações-produção, industrialização e análise. Nobel, São Paulo.

Berman, A. (2011). Invited review: Are adaptations present to support dairy cattle productivity in warm climates? Journal of Dairy Science, 94: 2147-2158.

Bernabucci, U. \& Calamari, L. (1998). Effects of heat stress on bovine milk yield and composition. Zootecnica e Nutrizione Animale, 24: 247-257.

Bilby, T. R., Tatcher, W. W. \& Hansen, P. J. (2009). Estratégias farmacológicas, nutricionais e de manejo para aumentar a fertilidade de vacas leiteiras sob estresse térmico. Anais do XIII Curso Novos Enfoques na Produção e Reprodução de Bovinos 1: 59-71.

BRASIL; Ministério da Agricultura, Pecuária e Abastecimento. Secretaria de Defesa Agropecuária. Departamento Nacional de Inspeção de Produtos de Origem Animal. Regulamento técnico de Identidade e Qualidade de Leite Pasteurizado. Instrução 
Normativa $\mathrm{n}^{\mathrm{o}} 51$, de 18 de setembro de 2002. Diário Oficial da União, Brasília, 20 set. 2002. Seção 1, p.13-22.

BRASIL. Instrução Normativa $\mathrm{n}^{\circ}$ 62, de 29 de dezembro de 2011. Áprovar o regulamento técnico de identidade e qualidade de leite tipo $\mathrm{A}$, o regulamento técnico de identidade e qualidade de leite cru refrigerado, o regulamento técnico de identidade e qualidade de leite asteurizado e o regulamento técnico da coleta de leite cru refrigerado e seu transporte a granel. Diario Oficial da Republica Federativa do Brasil. Brasília, Seção 1, p. 1-24.

Brito, M. A. V. P. (1999). Conceitos básicos de qualidade, sanidade do gado leiteiro. Minas Gerais: Embrapa.

Campos, R., Almeida, L. L., Terra, S. R. \& González, F. H. D. (2008). Parâmetros hematológicos e níveis de cortisol plasmático em vacas leiteiras de alta produção no Sul do Brasil. Brazilian Journal of Veterinary Research and Animal Science 45: 354-361.

Carvalho, S., Rodrigues, M. T., Branco, R. H. $\&$ Rodrigues, C. A. F. (2006). Consumo de nutrientes, produção e composição do leite de cabras da raça Alpina alimentadas com dietas contendo diferentes teores de fibra. Revista Brasileira de Zootecnia, 35, 11541161.

Ceballos, L. S., Moralesa, E. R., Adarvea, G. T., Castro, J. D., Martínez, L. P. \& Sampelayo, M. R. S. (2009). Composition of goat and cow milk produced under similar conditions and analyzed by identical methodology. Journal of Food Composition and Analysis, 22: 322-329.

Cerdótes, L., Restle, J., Alves Filho, D. C., Nörnberg, M. F. B. L., Nörnberg, J. L., Heck, I. \& Silveira, M. F.. (2004). Produção e composição do leite de vacas de quatro grupos genéticos submetidas a dois manejos alimentares no període de lactação. Revista Brasileira de Zootecnia, 33: 610-622.

Champagne, C. P., Laing R. R., Roy, D., Mafu, A. A. \& Griffiths, M. W. (1994). Psychrotrophs in dairy products: their effects and their control. Critical reviews in food science and nutrition, 34: 1-30.
Chen, L., Daniel, R. M. \& Coolbear, T. (2003). Detection and impact of protease and lipase activities in milk and milk powders. International Dairy Journal, 13: 255-275.

Chen, S. X., Wang, J. Z., Van Kessel, J. S., Ren, F. Z. \& Zeng, S. S. (2010). Effect of somatic cell count in goat milk on yield, sensory quality, and fatty acid profile of semisoft cheese. Journal of Dairy Science, 93: 1345-1354.

Collier, R. J. (1985). Nutritional, metabolic, and environmental aspects.

Fagan, E. P., Jobim, C. C., Júnior, M. C. Silva, M. S. \& Santos, G. T. (2010). Environmental and handling factors on the chemical composition of milk in dairy farms of Paraná State, Brazil. Revista Brasileira de Zootecnia, 32: 309-316.

FAO. (2015). Statistical Yearbook. Food and Agriculture Organization of the United Nations, Rome, Italy.

Froeder, E., Pinheiro, A. J. R. \& Brandão, S. C. C. 1985. Variação da qualidade microbiológica do leite cru tipo $\mathrm{C}$ da Região de Viçosa. Revista do Instituto Cândido Tostes 40: 55-68.

Glantz, M., Lindmark Månsson, H., Stålhammar, H., Bårström, L.O., M. Fröjelin, M., Knutsson, A., Teluk, C. \& Paulsson, M. (2009). Effects of animal selection on milk composition and processability. Journal of Dairy Science, 92: 4589-4603.

Goetsch, A. L., Merkel, R. C. \& Gipson, T. A. (2011). Factors affecting goat meat production and quality. Small Ruminant Research, 101: 173-181.

Gomes, S. T. (1999). Diagnóstico $e$ perspectivas da produção de leite no Brasil. MCT/CNPQ/PADCT 1: 19-35.

González, F. H. D., Durr, J. W. \& Fontanelli, R. (2001). Uso do leite para monitorar a nutrição e o metabolismo de vacas leiteiras, Porto Alegre.

Head, H. H. (1989). The strategic use of the physiological potential of the dairy cow. Simpósio Leite nos Trópicos: novas estratégias de produção No. 1. p 38-89. UNESP, Botucatu. 
Huber, J. T. (1990). Alimentação de vacas de alta produção sob condições de estresse térmico. In: ESALQ (ed.) Bovinocultura Leiteira. p 33-48. FEALQ, Piracicaba.

Jordan, E. R. (2003). Effects of heat stress on reproduction. Journal of Dairy Science, 86: E104-E114.

Machado, P. F. (1998). Efeitos da alta temperatura sobre a produção, reprodução e sanidade de bovinos leiteiros. In: Ambiência na produção de leite em clima quente, Piracicaba. p 179-188.

Machado, P. F., Pereira, A. R. \& Sarríes, G. A. (2000). Composição do leite de tanques de rebanhos brasileiros distribuídos segundo sua contagem de células somáticas. Revista Brasileira de Zootecnia, 29: 1883-1886.

Marcheto, F. G., Nääs, I. A. Salgado, D. D. \& Souza, S. R. L. (2002). Efeito das temperaturas de bulbo seco e de globo negro e do índice de temperatura e umidade, em vacas em produção alojadas em sistema de free-stall. Brazilian Journal of Veterinary Research and Animal Science, 39: 320-323.

McGuire, M. A., Beede, D. K., DeLorenzo, M. A., Wilcox C. J., Huntington, G. B., Reynolds, C. K. \& Collier, R. J. (1989). Effects of thermal stress and level of feed intake on portal plasma flow and net fluxes of metabolites in lactating Holstein cows. Journal of Animal Science, 67: 1050-1060.

Monardes, H. (2008). Controle leiteiro e qualidade do leite. In: $3^{\circ}$ Congresso Brasileiro de Qualidade do Leite, Recife. $\mathrm{p}$ 115-127.

Nääs, I. A. \& Arcaro Júnior, I. (2001). Influência de ventilação e aspersão em sistemas de sombreamento artificial para vacas em lactação em condições de calor. Revista Brasileira de Engenharia Agrícola e Ambiental, 5: 139-142.

Nero, L. A., Mattos, M. R., Beloti, V., Barros, M. A. \& Franco, B. D. G. (2007). Resíduos de antibióticos em leite cru de quatro regiões leiteiras no Brasil. Ciencia $e$ Tecnologia de Alimentos, 27: 391-393.

Nickerson, S. C., Owens, W. E. \& Boddie, R. L. (1995). Mastitis in dairy heifers: initial studies on prevalence and control. Journal of Dairy Science, 78: 1607-1618.

Noro, G., González, F. H. D., Campos, R. \& Dürr, J. W. (2006). Fatores ambientais que afetam a produção e a composição do leite em rebanhos assistidos por cooperativas no Rio Grande do Sul. Revista Brasileira de Zootecnia, 35: 1129-1135.

Oliveira, C. A. F., Fonseca, L. F. L. \& Germano, P. M. L. (1999). Aspectos relacionados à produçäo, que influenciam a qualidade do leite. Higiene Alimentar, 13: 10-16.

Padilha, M. R. d. F., \& Fernandes, Z. F. (1999). Avaliaçäo da qualidade higiênicosanitária do leite tipo comercializado no Recife - PE. Higiene Alimentar, 13: 105109.

Pereira, A. R., Prada, L. F., Molon, L. K., Machado, P. F. \& Barancelli, G. (1999). Efeito do nível de células somáticas sobre os constituintes do leite I-gordura e proteína. Brazilian Journal of Veterinary Research and Animal Science, 36: 121124.

Perissinotto, M., Moura, D. J., Matarazzo, S. V., Silva, I. J. O. \& Lima, K. A. O. (2006). Efeito da utilização de sistemas de climatização nos parâmetros fisiológicos do gado leiteiro. Engenharia Agrícola, 26: 663-671.

Pinarelli, C. (2003). The effect of heat stress on milk yield. Latte, Milan 28: 36-38.

Pires, M. F., Ferreira, A. M., Saturnino, H. M. \& Teodoro, R. L. (2002). Taxa de gestaçäo em fêmeas da raça Holandesa confinadas em free stall, no veräo e inverno. Arquivo Brasileiro de Medicina Veterinária $e$ Zootecnia, 54: 57-63.

Ponce, P. (2009). Composición láctea y sus interrelaciones: expresión genética, nutricional, fisiológica y metabólica de la lactación en las condiciones del trópico. Revista de Salud Animal, 31: 69-76.

Ponsano, E. H. G., Pinto, M. F. Lara, J. A. F. \& Piva, F. C. (1999). Variaçäo sazonal e correlaçäo entre propriedades do leite utilizadas na avaliaçäo de qualidade. Higiene Alimentar, 13: 35-39. 
Porcionato, M. A. F., Fernandes, A. M. Netto, A. S. \& dos Santos, M. V. (2009). Influência do estresse calórico na produção e qualidade do leite. Revista Acadêmica: Ciência Animal, 7: 483-490.

Porto, P. P., Deresz, D., Santos, G. T., Lopes, F. C. F., Cecato, U. \& Cóser, A. C. (2009). Milk production, milk composition, intake and digestibility of tropical forages under intermittent grazing system. Revista Brasileira de Zootecnia, 38: 1422-1431.

Prada, L. F., Pereira, A. R., Machado, P. F. \& Sarriés, G. A. (2000). Efeito do nível de células somáticas sobre os constituintes do leite II-lactose e sólidos totais. Brazilian Journal of Veterinary Research and Animal Science, 37: 330-333.

Sá, O. R., França, M., Esper, K C. P., Pereira, K C., Souza, N. C. \& Silva, T. M. (2011). Avaliação da qualidade higiênico-sanitária do leite cru refri gerado produzido em propriedades leiteiras do município de Passos e região. Revista Ciência et Praxis, 4: 23.

Santos, E. R. \& Ribeiro, A. G. (2004). Clima e agricultura no município de Coromandel (MG). Caminhos de Geografia, 8: 122140.

Silva, H. A., Moraes, H. S. K. A., Hack, V. A. G. E. \& Faccio, P. C. F. (2008). Análise da viabilidade econômica da produção de leite a pasto e com suplementos na região dos
Campos Gerais-Paraná. Ciência Rural, 38 : 445-450.

Silva, N., Junqueira, V. C. A. \& Silveira, N. F. A. (1997). Manual de Métodos de Análise Microbiológica de Alimentos. Editora Varela, Campinas, Brazil.

Titto, E. A. L. (1998). Clima: Influência na produção de leite. Simpósio Brasileiro de Ambiência na Produção de Leite 1: 10-23.

Tronco, V. M. (2008). Manual para inspeção da qualidade do leite. UFSM.

Uribe-Velásquez, L. F., E. Oba, L. H. Albuquerque Brasil, F. N. Sousa, \& F. S. Wechsler. (2001). Efeitos do estresse térmico nas concentrações plasmáticas de progesterona (P4) e estradiol 17- b (E2) e Temperatura Retal em Cabras da Raça Pardo Alpina. Revista Brasileira de Zootecnia, 30: 388-393.

Vaclavik, V. A. \& Christian, E. W. (2007). Essentials of Food Science. Springer.

\section{Article History:}

Received 17 June, 2016

Accepted 13 July, 2016

Available on line 18 August, 2016

License information: This is an open-access article distributed under the terms of the Creative Commons Attribution License, which permits unrestricted use, distribution, and reproduction in any medium, provided the original work is properly cited. 